\title{
Mobile Cockpit System for Enhanced Electric Bicycle Use
}

\author{
João C. Ferreira, Member, IEEE, Vítor Monteiro, Student Member, IEEE, \\ José A. Afonso, Member, IEEE, João L. Afonso, Member, IEEE,
}

\begin{abstract}
This paper presents the project of a Mobile Cockpit System (MCS) for smartphones, which provides assistance to Electric Bicycle (EB) cyclists in Smart Cities' environment. The presented system introduces a mobile application (MCS App) with the goal to provide useful personalized information to the cyclist related with the EB's use, including EB range prediction considering the intended path, management of the cycling effort performed by the cyclist, handling of the battery charging process and the provisioning of information regarding available public transport. This work also introduces the EB cyclist profile concept, which is based on historical data analysis previously stored in a database and collected from mobile devices sensors. From the tests performed, the results show the importance of route guidance, taking into account the energy savings. The results also show significant changes on range prediction based on user and route taken. It is important to say that the proposed system can be used for all bicycle in general.
\end{abstract}

Index Terms-Smartphone Sensing, Cyclist Profile, Electric Bicycle, Mobile Cockpit System, Public Transport, Range Prediction.

\section{INTRODUCTION}

The electric mobility area, particularly Electric Vehicles and Hybrid Vehicles [1][2], with battery scheduling strategies [3] based on electricity prices [4], has raised the citizens' interest in the last years, as part of the policy to reduce the greenhouse gas emissions [5][6] and improve energy management [7]. More recently, the interest in the electrification of

Manuscript received November 26, 2014.

Copyright (c) 2009 IEEE. Personal use of this material is permitted. However, permission to use this material for any other purposes must be obtained from the IEEE by sending a request to pubspermissions@ieee.org.

João Ferreira is with Centro Algoritmi, University of Minho and GuIAAISEL, Lisbon Portugal. Rua Conselheiro Emídio Navarro 1, 1900-049 Lisboa; e-mail: jferreira@deetc.isel.ipl.pt.

Vítor Monteiro and João L. Afonso are with Centro Algoritmi, University of Minho, Dept. Industrial Electronics, 4800-058 Guimarães, Portugal; emails: vmonteiro@dei.uminho.pt and jla@dei.uminho.pt.

José A. Afonso is with CMEMS-UMinho, University of Minho, 4800-058 Guimarães, Portugal; e-mail: jose.afonso@dei.uminho.pt.

This work has been supported by FCT - Fundação para a Ciência e Tecnologia in the scope of the projects: PEst-UID/CEC/00319/2013 and UID/EEA/04436/2013, and the doctoral scholarship SFRH/BD/80155/2011 granted by the FCT agency. transportation [8] is also focused on new vehicles for indoor mobility [9], light Electric Vehicles [10], and Electric Bicycle (EBs) $[11][12][13]$. Electric mobility also provides an important contribution to smooth the intermittent energy production from renewable sources [13][14]. On the other hand, information systems to share data between the users and these vehicles are one of the main requirements to the full adoption of electric mobility [15][16][17]. Since the last decade, most citizens use cell phones for several purposes, including access to web services and search engines. This new approach has also been adopted to interact with the user in order to provide information related with his/her daily habits. In this scenario, the in-car infotainment sector has also been presenting several solutions to establish communication between their equipment and the users' cell phones. Thus, the development of solutions based on Information and Communication Technologies (ICT) will be a key factor for the development of Smart Cities and Smart Grids [18][19].

Nowadays, smartphones are much more than simple devices to communicate and access the Internet. They are equipped with several sensors capable of providing relevant information related with motion, orientation, and environmental conditions, and can also collect data via wireless form nearby external sensors. The main sensors that are available in the smartphones are: microphones, cameras, accelerometers, gyroscopes, magnetometers, proximity, Global Positioning System (GPS), light and temperature sensors. These sensors are incorporated in the smartphone mainly due to their reduced size and low power consumption. External sensors include wearable sensors used to monitor parameters such as heart rate or motion [20], as well as environmental sensors such as temperature or humidity sensors.

One of the first works aimed at enhancing the cyclist's experience through the use of smartphone sensing was the BikeNet system [21]. This system, which is based on a conventional bicycle, provides the collection of data from multiple sensors, such as the cyclist's stress level, the speed and the position, as well as the $\mathrm{CO}_{2}$ and noise levels. The collected data is uploaded to a repository and shared with the cycling community through a web portal.

Another relevant work in this area is the Copenhagen Wheel project [22], which provides a wheel that can be adapted to a conventional bicycle in order to convert it into an electric bicycle. The wheel hub integrates the electric motor, battery and inner gears, as well as humidity, noise, temperature, $\mathrm{CO}$ 


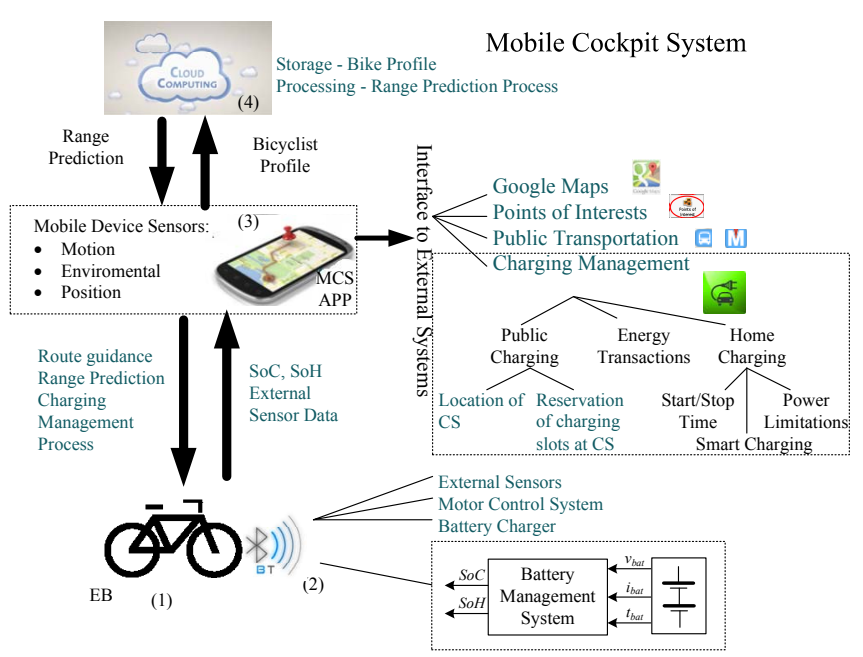

Fig. 1. Overview of the proposed Mobile Cockpit System (MCS).

and NOx (nitrogen oxides) sensors. An iPhone smartphone communicates with the wheel via Bluetooth, allowing the cyclist to collect sensor data, lock the bicycle and control the gears and the motor.

The Mobile Cockpit System (MCS) proposed in this paper is an integrated project that gathers a set of developments from different engineering areas such as computers and industrial electronics. Related with computer engineering, the main technological areas addressed are smartphone sensing, navigation support, cyclist profile, and public transport information. On the other hand, related to industrial electronics engineering, the areas addressed are the EB prototype, the battery charging system and the Bluetooth communication to the sensors that are used to determine the cyclist's performance based on fitness measurements. In this context, the MCS is directed to EBs and aims to assist the cyclists in the Smart Cities environment. This environment demands the usage of several transportation modes in an integrated way, where the bicycle plays an important role, especially in the central part of the city, in the areas closed to private transportation [23]. Although the EB allows transportation in the city with moderate effort, due to the assistance of its electric engine, it still has the problem of limited range autonomy, due to limited energy storage capacity in the batteries. For example, the nominal energy that can be stored in the battery of our EB prototype is $360 \mathrm{Wh}$; therefore, in normal road, weather and riding conditions, the range autonomy of the $\mathrm{EB}$ is around $29 \mathrm{~km}$.

EBs fit in the business model of private transportation or as bicycle sharing. For both scenarios, the developed Mobile Cockpit System provides, in real time, information regarding range autonomy, battery State-of-Charge (SoC), route advice, as well as information on nearby public transport available and Points-of-Interest (POI). EBs mainly associated with a bicycle sharing system can play an important role in the mobility process of modern cities. Insufficient public transport offer can be mitigated using EBs, with personalized routes and small effort by the cyclist due to the electric engine. The system's mobile application module (MCS App) can be used with any bicycle and can offer an integrated real time view of the current transportation options available. Like other works [21][22], the MCS system also explores the contribution of the information provided from multiple sensors. Another important research topic is the access to real time traffic information. This information, obtained from navigation systems, contributes to the MCS in terms of route planning, driving guidance and safety. Fig. 1 shows an overview of the proposed system.

\section{Mobile CockPit System Project}

The MCS project consists in the development of a solution that supports cyclists with appropriate and relevant information to decide and plan their journeys using EBs. Through the MCS, the constraints related with the EB range autonomy are minimized, contributing to avoid the phenomenon of range anxiety. This phenomenon is associated to the user's fear of not be able to reach the desired destination due to insufficient energy stored in the battery.

The MCS increases the amount of information available, according to the cyclists' needs, because this information is a key part of their decision process. It can also be complemented with information from external sensors installed in the bicycle and in the cyclist, transmitted via Bluetooth to the MCS App installed on the cyclist's mobile device. These sensors can be implemented in the bicycle crank to measure cadence (rpm) and the torque applied (Nm). Based on these two measurements, it is possible to calculate the power (torque multiplied by angular speed), which corresponds to the cyclist's effort. For example, a torque of $75 \mathrm{Nm}$ and an angular speed of 4 radians per second (corresponding to a cadence of about $38 \mathrm{rpm}$ ) result in a power of $300 \mathrm{~W}$. It is also possible to measure the cyclist's heart rate (in bpm).

The main modules of the MCS project, identified in Fig. 1 are: (1) EB that was developed in the period of one year in a MSc Thesis from Minho University (Portugal); (2) interface and communication system to exchange data with the cyclist, EB, and central server; (3) MCS App developed for the Android operating system, which is used to present the EBrelated information and to collect data from the mobile device sensors; (4) Cloud computing module, used for data storage and heavy processing, since mobile devices have limited storage and processing capacity.

The research work presented establishes links between energy and transportation systems (from Minho University), and information and communication technologies (from ISEL in Lisbon). The main goal is oriented to the centralization of relevant information in a mobile application because, in the current reality of Smart Cities, the users need more and better information in real time. There is a need to be interconnected in spatial-temporal dimensions, taking into account their differences and categories, and exploring the integration of available transportation information services with digital information concerning the urban space and its dynamics, in order to provide innovative ubiquitous services for mobility and transportation. The MCS App will play an important role in this process, taking into account that there were already 6.8 


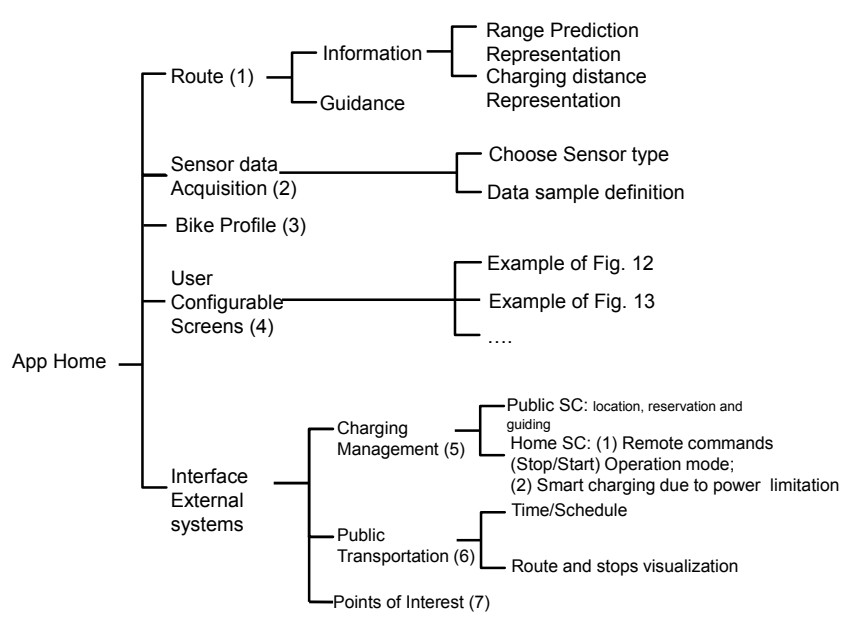

Fig. 2. Main menu of the MCS App available at the mobile device.

billion mobile subscriptions worldwide in 2013 (around 96\% of world population) [24].

In this sequence of ideas, the main goal of the project presented in this paper is the development of a mobile application oriented to the integration of the EB in the mobility process. This application integrates information from different external and internal sources.

Fig. 2 represents the main menu of the MCS App, with an overview of the functionalities available: (1) Route guidance for Points-of-Interest (POI), charging stations and destination, as well as information on the distance that is possibly achieved with the actual battery State-of-Charge (SoC) level (range prediction representation) or the $\mathrm{SoC}$ level needed to reach a defined destination (charge distance representation); (2) Define data and acquisition interval from the available sensors; (3) View information regarding the cyclist's profile; (4) Configure the application menu to obtain personalized data based on the available functions; (5) Manage the charging process in public stations (through the location, guiding information and slot reservation) and at home (charging the device with the possibility of remote start/stop commands, as well as smart charging, taking into account power limitations and electricity prices); (6) Public transport information, with scheduling of route paths and bus stop locations; and (7) Representation of Points-of-Interest (POI).

\section{EleCtric BiCyCle PROTOTyPe}

The EB plays an important role in the present society, because it is a cheap, versatile, healthy-to-use, and environmentally friendly vehicle, which represents an ideal means of transportation for short distances. In this context, an EB prototype was developed and aimed to be used as a platform to test concepts related with the EB and its interaction with cyclists. This is also a complementary work to previous developments which were performed in the electric vehicle area [25], with the goal to centralize and personalize all the information related with the mobility process in the Smart Cities' environment. This section describes the EB prototype that was used as a case study in this paper and which is shown in Fig. 3.

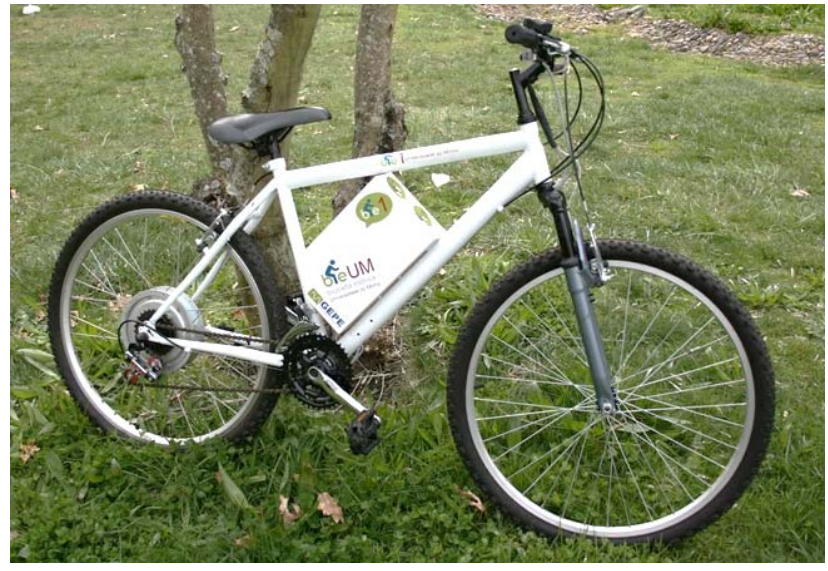

Fig. 3. EB prototype used as case study.

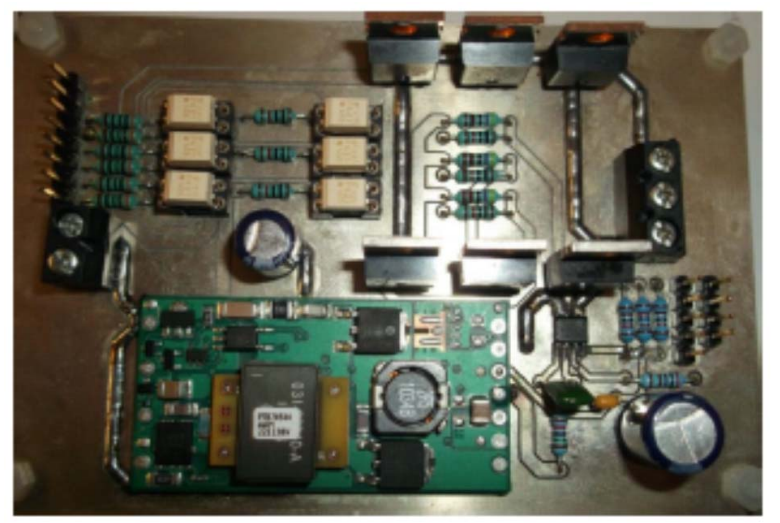

Fig. 4. Motor drive hardware.

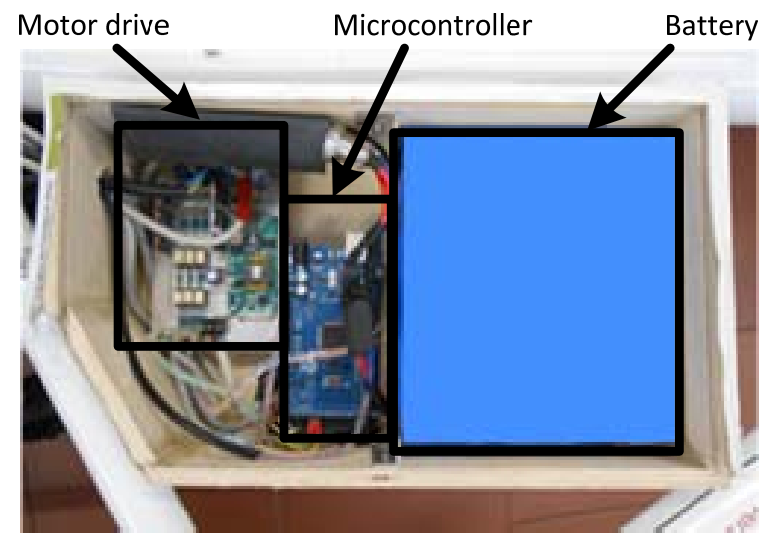

Fig. 5. Box of the EB prototype with the motor drive board, the microcontroller board and the battery.

\section{A. Motor Control System}

The algorithms of the motor control system were implemented in the microcontroller ATmega2560. These algorithms are based on the information obtained from: hall-effect sensors, current sensors, selected help mode, and the pedal-board sensor. If the EB brakes are actuated, it is verified if the user is pedaling and, according with the help mode, the motor control duty-cycle is adjusted up to the maximum speed of $25 \mathrm{~km} / \mathrm{h}$. The motor drive hardware consists in a three-phase full-bridge converter with 6 MOSFETs ( 3 of n-type and 3 of p-type). This power converter hardware is shown in Fig. 4. Fig. 5 shows the box where the 
complete motor control system of the EB is placed, in which the motor drive board, the microcontroller board and the battery are seen.

\section{B. Battery Charger}

The battery charger that was implemented consists in a traditional AC-DC converter combined with a DC-DC boost converter. With the DC-DC converter it is possible to adjust the current or the voltage in order to perform an adequate battery charging process. This EB uses a lithium-polymer battery with a nominal voltage of $36 \mathrm{~V}$ and a nominal capacity of $10 \mathrm{Ah}$. This battery charger allows the measurement of the battery current and voltage, as well as the temperature, and uses these parameters to estimate the instantaneous value of the battery State-of-Charge (SoC). The charging algorithm follows the recommendation from the battery manufacturer, being composed by two stages: constant current and constant voltage. Fig. 6 shows the battery charger that was developed for the EB. In order to avoid extra weight to the EB, the battery charger is on the outside of the EB. Fig. 7 shows the experimental results obtained during a charging process of this battery at a charging rate of $0.3 \mathrm{C}$.

\section{EB INTERFACE AND COMMUNICATION SYSTEM}

Taking into account the necessary data transfer between the EB and the cooperative infrastructure (MCS App and Cloud Computing, see Fig. 2), a common API for communications, named "ElectricBike2Infrastruture" (EB2I), was developed. This developed API also aims to be a standard that could be used with all EBs. For such a purpose several parameters were set to carry information, and an XML (Extensible Markup Language) file structure was created. Part of the information is related with the battery (voltage, current, and temperature) and the electric motor (speed and torque).

In the scope of this paper, the Bluetooth wireless technology was used to transmit data from the EB to the MCS App, while Wi-Fi was used to transmit data from the MCS App to the central web server. The MCS App defines userspecific interfaces, which are implemented as activities. The application has the following functionalities (a complete description is presented in [26]): (1) Information Services, such as battery SoC and State-of-Health ( $\mathrm{SoH})$ evaluation, range prediction, charging management and energy; (2) Public transport information; (3) Energy Broker; and (4) Points-of-Interest (POI).

\section{A. Charging Management Interface}

The role of the EB battery management system in the MCS is extremely relevant, because this system is responsible for providing information related with the battery SoC and $\mathrm{SoH}$. These parameters are calculated based on the information obtained from voltage, current, and temperature sensors, which are installed in the battery charger. This information is used to predict the range autonomy according to the cyclist's profile and the desired destination. As aforementioned, the communication between the battery management system and the smartphone is done via Bluetooth. Since the smartphone

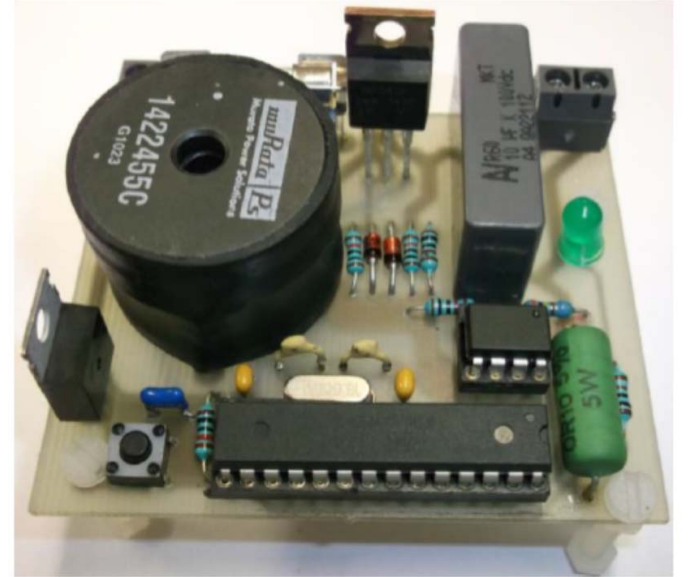

Fig. 6. Developed battery charger.

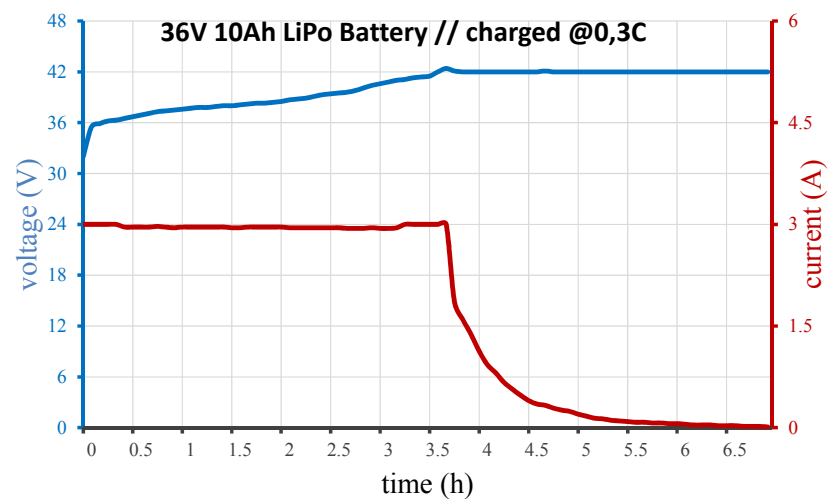

Fig. 7. Experimental results of the battery charging process.

has limited storage capacity, a web service was developed to support the data submission to a SQL database in a central storage server. All this information is used to interact with the user through a mobile device that can be carried by the cyclist in or out of the EB. Regarding the EB battery charging management, it is divided into three main subjects:

1. Charging Station: Consists in finding public charging stations, determine their availability and guide the cyclist to them;

2. Home Charging Control: Consists in starting and stopping the battery charging progress at home, according to the cyclist's preferences in terms of schedules;

3. Charging Process: The energy to perform the EB battery charging process is provided by the power grid and is adjusted to the battery levels through an AC-DC converter, as described in section III.B.

\section{B. Public Transport Interface}

The integration of public transport information is used to provide the cyclist with information related to schedules from different sources of public transport. It can be used by the cyclist to plan his journey with the EB. This solution is based on a previous work of integration of public transport information with electric vehicles [27]. Fig. 11 shows an example of this interaction and Fig. 8 shows a georeferenced graph approach to perform this feature [28]. Different information is stored in georeferenced layers: (1) Information 


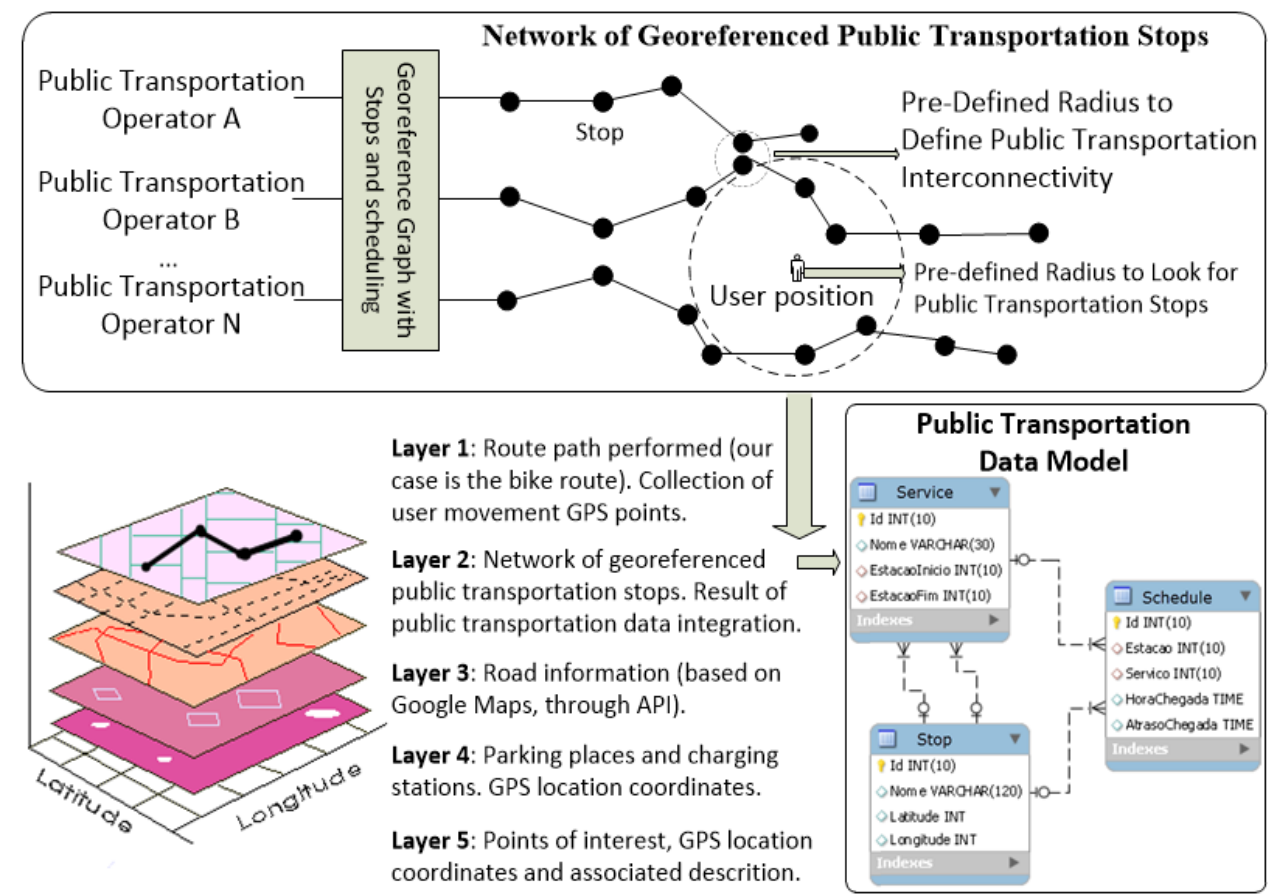

Fig. 8. Multimodal Graph approach for data integration among public transport and other transportation systems. Transportation interconnectivity is determined by stops with a distance less than a pre-defined value. It is represented the data model for data exchange among different public transport operators.

of user movements based on GPS data of the user's mobile device; (2) Multimodal transportation layer created based on the integration of different transportation operators. Operator interconnectivity is based on the geographic distance among public transport stops (in the current approach we use a distance of 50 meters, based on a linear distance to public transport stops). This process is performed once and then the information is stored in a graph layer, using the data model defined in Fig 8; (3) Road infrastructure layer. In our approach we use Google Maps API to get this information; (4) GPS coordinates of parking places, facilities and charging stations; and (5) POI information, with GPS coordinates and a small description. Interaction among these layers allows the user to look for the following, nearby: (a) public transport; (b) parking places; (c) charging station; and (d) POI.

The integration of data from the public transport and its availability on mobile devices can create better conditions and new incentives for cyclists. As for example, due to bad weather conditions or a route with considerable accumulated slopes, the cyclist can use the public transport as complementary transport. Nevertheless, it is difficult to obtain integrated information related with public transport, because each operator has its own system with independent schedules and routes. In this context, an interface capable to interrogate multiple sources of information was developed in a previous START project [http://www.start-project.eu/en/Home.aspx], using data from project partners in Portugal, Spain, France, and England.

\section{Points-of-Interest (POI) Interface}

The user has the option of selecting possible Points-ofInterest (POI) to visit nearby. To do so, the cyclist needs to know which route to use in order to visit these Points-of-
Interest (POI). Therefore, a database of POI in Portugal, which includes geographic location and a small description, was loaded. A screen for the users to look for POI in a predefined radius from the current position was developed [27], [28]. The application indicates possible routes and also indicates the travel time and distance. For each route, it is possible to see the steps needed to guide the user during the journey in order to reach the target location. Optionally, the user can observe this route on a geographical map.

\section{Developed Mobile ApPlication}

The MCS App was developed in order to represent the user information related with: (1) Charging management; (2) Range autonomy; (3) Route guidance, taking into account the available energy in the battery and the route altitude; (4) Public transport information; (5) Sensors information; and (6) Route information. Moreover, the mobile device sensors are used to collect cyclist motion information. This application was developed on the Android platform. The user defines the information related with the sensors to use, the sample interval, as well as the login, password, email and profile data based on past data acquired and stored in our database.

\section{A. Mobile Sensors Information}

The main function of this module is to use the available sensors on the mobile phones to collect information with the respective metadata of time and location. Some of the data that can be obtained is related with current speed, average speed, distance traveled, path inclination, and heart rate (locally developed sensor at ISEL [29]). Nowadays, almost all of mobile devices have incorporated sensors, which are based in three main categories: motion; environmental conditions; and position. The sensors' interaction with the mobile device is 


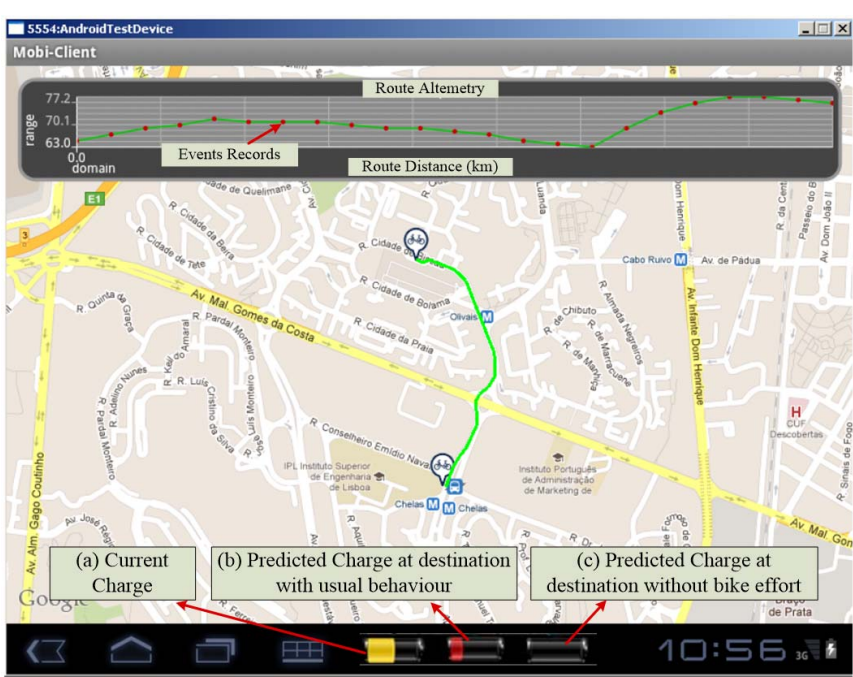

Fig. 9. MCS App screen with information of route path and associated topology: (a) Information of the current battery SoC; (b) Information about predicted charge at destination taking into account the previous cyclist effort that is available in his profile; (c) Predicted charge information at destination without any cyclist effort.

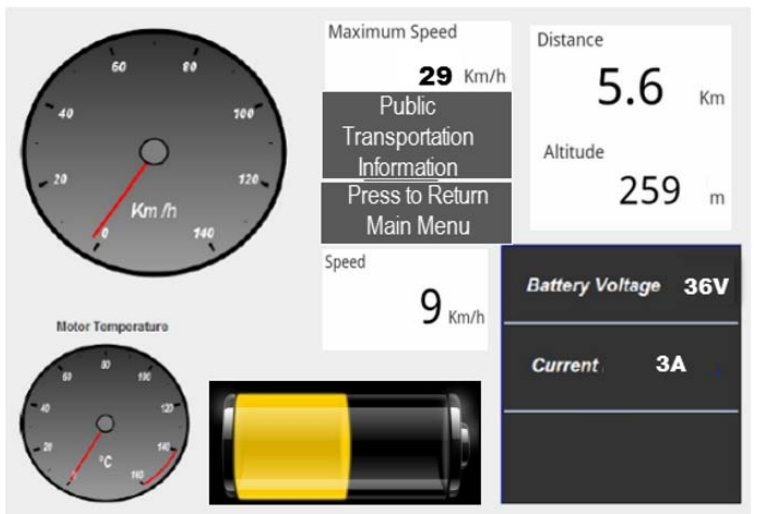

Fig. 10. Screen of the mobile application with speedometer, altimetry and charging related information.

dependent on the operating system. As aforementioned, in this project the Android platform was used due to the available framework, which provides several classes and interfaces that are useful to develop applications. The selection of the sensors is a user option. The developed application detects the available sensors and an application menu shows the user the available sensors and the option to select the desired ones, as well as the sampling time interval. Table I shows the sensors used on the current project for Android 4.0. Since most EBs do not have a speedometer, the idea is to measure the speed based on GPS data calculation. Sensors are also used to measure acceleration (with an accelerometer sensor), check position and altitude (both from GPS data), as well as temperature and pressure (when these sensors are available). All the data obtained from these sensors is stored locally in a SQLite database (during the acquisition phase) and transmitted to a central server when the acquisition process is finished. This data, which provides useful information for the mobility process, is partially stored in the cyclist's profile (speed, altitude, position, distance performed, average cadence, heart rate, date, time, start and end location of each trip), and can also be used for the automatic determining of transportation mode (e.g., bus, car, walking, bicycle, train) [30], and to classify the user's activity [31].

\section{B. MCS App Screens}

Taking into account the public information availability, it is possible to integrate several sources in the Lisbon area, and have the various public transport stops shown on a map in real time, as well as the waiting time for each of the services. Fig. 11 shows the results of a query about nearby public transport. As shown, the system presents the waiting time and location. The study of the slope is particularly relevant for cyclists. Another important use of the MCS App is to check a route to a desirable destination, taking into account not only the current position, but also the altitude of the current route, because this influences both the energy consumption and the cyclist's effort. Thus, based on barometer sensor and GPS information, an XML file is constructed and sent to the central server. This information is used to create the map with the altitude information illustrated in Fig. 9, where the output of a route suggestion with the associated topology is represented. The information path associated with altitude is represented on top, and information of the remaining battery energy at the destination on the bottom for two scenarios: without human effort; and taking into account the effort usually applied by the cyclist, which is stored in the cyclist's profile. The application also handles the battery charging management, giving guidance and control to the charging process. There is a function that defines the energy from the battery needed to reach the desirable destination.

Cyclists can also define the information that they would want to appear on some of the predefined screens. Fig. 10 is an example where information about speed, altitude, and battery SoC is presented. Users can choose the information to be shown on the application screen based on the available defined functions such as: speed, battery SoC level, range information (without the cyclist's effort or based on the usual behavior available on the cyclist's profile), public transport information, time, altitude information of the represented route, location of public transport stops, among others.

\section{Cloud COMPUTING}

Due to the limited data storage and processing capacity on mobile devices, a cloud computing approach was applied to store data (the cyclist's profile) and perform range prediction processing on a services-based approach. This cloud computing approach avoids the cost of database and computer processing and maintenance. Due to the current development on cloud computing [32], decreasing prices and flexible development, the developed server is based on three different layers: (1) User Interface, mainly for presentation; (2) Web Services, for the services layer with business logic; and (3) Background Services, for process running in the background. The presentation layer has two feature modules, a module with features for the administrator and another for common users. The development was made on Microsoft Azure, because Microsoft provides a framework and a set of integrated tools 
TABLE I. Android Sensors Used on Current Project and Their Briefly Description

\begin{tabular}{c|c}
\hline $\begin{array}{c}\text { ANDROID } \\
\text { SENSORS }\end{array}$ & DESCRIPTION \\
\hline \hline Accelerometer & $\begin{array}{c}\text { Measures the acceleration force that is applied to a } \\
\text { device on all three physical axis including gravity }\end{array}$ \\
\hline Temperature & $\begin{array}{c}\text { Measures the temperature of the device } \\
\left.\text { in degrees Celsius ( }{ }^{\circ} \mathrm{C}\right)\end{array}$ \\
\hline Gravity & $\begin{array}{c}\text { Measures the force of gravity that is applied to a device } \\
\text { on all three physical axis }\end{array}$ \\
\hline Gyroscope & $\begin{array}{c}\text { Measures the device rate of rotation around each of the } \\
\text { three physical axis }\end{array}$ \\
\hline Linear Acceleration & $\begin{array}{c}\text { Measures the acceleration force that is applied to a } \\
\text { device on all three physical axis, excluding the force of } \\
\text { gravity }\end{array}$ \\
\hline Magnetic field & $\begin{array}{c}\text { Measures the environment's geomagnetic field for all } \\
\text { three physical axis }\end{array}$ \\
\hline Orientation & $\begin{array}{c}\text { Measures the degrees of rotation that a device makes } \\
\text { around all three physical axis }\end{array}$ \\
\hline Pressure & $\begin{array}{c}\text { Measures the environment's air pressure } \\
\text { in percentage (\%) }\end{array}$ \\
\hline Humidity & Measures the relative environments humidity \\
\hline Rotation vector & $\begin{array}{c}\text { Measures the orientation of a device by providing the } \\
\text { three elements of the device rotation vector }\end{array}$ \\
\hline \hline
\end{tabular}

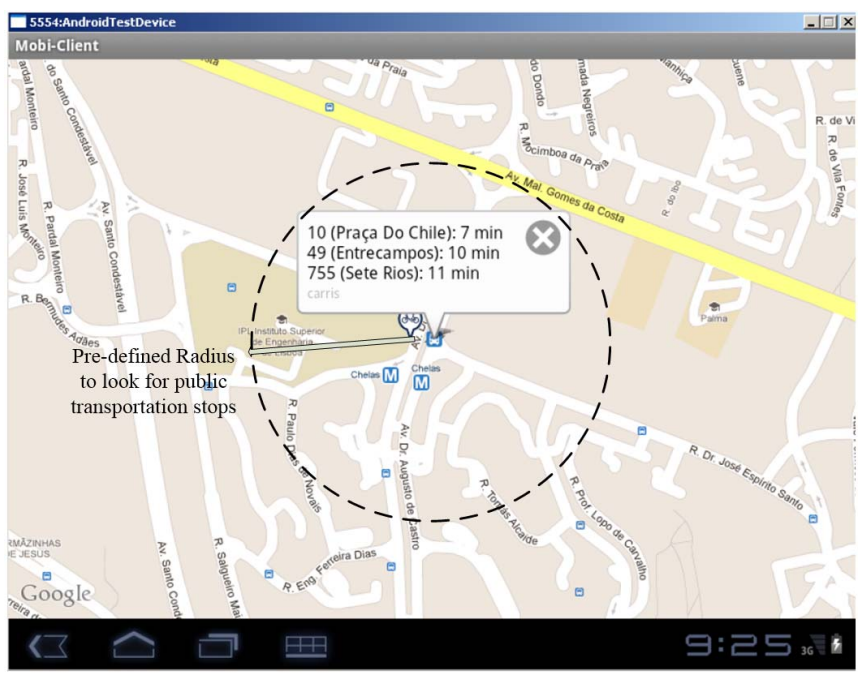

Fig. 11. MCS App screen showing the current cyclist's position (bicycle symbol), nearby public transport stops and indication of bus waiting times. The $\mathrm{M}$ letter corresponds to underground (Metro) stations in Lisbon, and the bus symbol to bus stops)

with Visual Studio, as well as a simulator, which allows the development and testing of applications created in the Cloud.

\section{A. Cyclist's Profile}

The cyclist's profile is based on the information collected from the mobile device sensors and external sensors, user input (personal identification) and from the bicycle battery status (SoC and $\mathrm{SoH}$ ). Table II shows the main parameters that are stored in a cyclist's profile. This cyclist profile can be used to better understand the bicycle riding process, and to study
TABLE II. Main Parameters Stored in a cyclist Profile

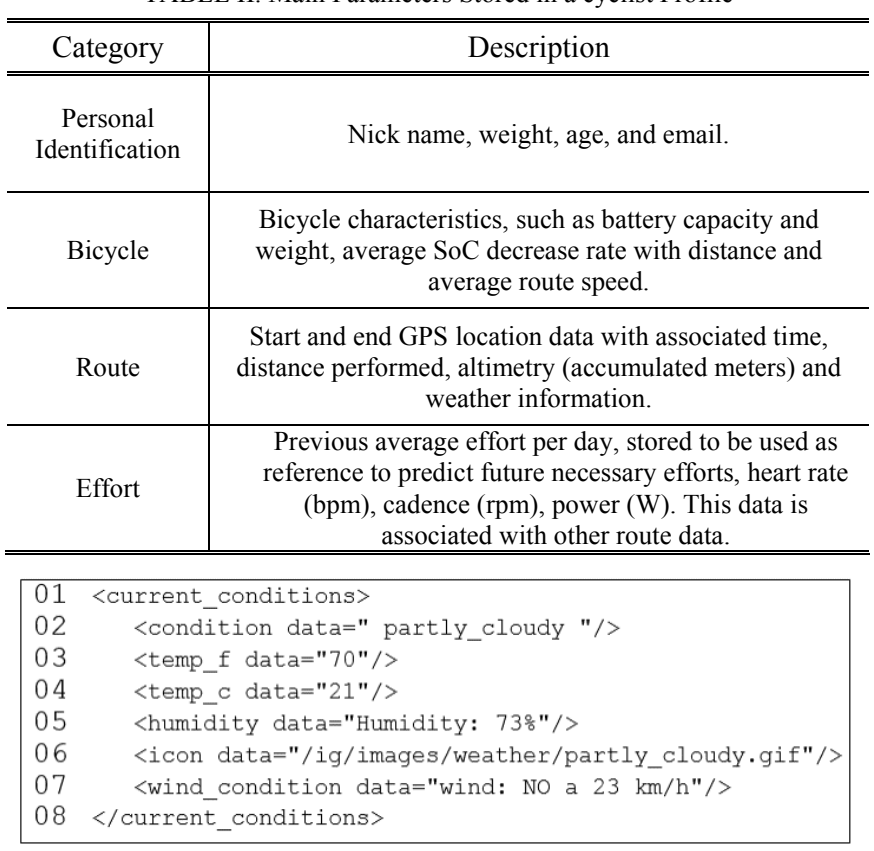

Fig. 12. Example of weather information excerpt in standard XML format, obtained from a weather web site.

the differences among the cyclists.

This profile plays an important role in the range prediction process, which is based on three main components: (1) Cyclist route (distance performed) and its altitude information (accumulated meters); (2) Previous cyclist effort measured by cadence $(\mathrm{rpm})$ and torque $(\mathrm{Nm})$ sensors, from where the power (W) is calculated; (3) Weather data. All this information is stored for later calculation of the average cyclist effort applied on his trip, and the relations among these variables are taken into account in the range prediction process.

The weather is also an important variable. On days that are rainy or too hot, the cyclists normally avoid riding. Wind speed and direction are important parameters for range prediction. Weather data is taken from temperature, pressure, and humidity sensors and complemented with weather site information, taking into account the current user's position. This information is stored in an XML file (see Fig. 12). The weather information was collected from the weather web site Wunderground <http://www.wunderground.com>, which has an API that allows access to atmospheric conditions given the coordinates of a location; thus, it is not necessary to get the name of a city purposely in order to consult the weather information.

User data privacy for this tracking activity is an important concern, which increases in the context of mobile devices. Therefore, all information concerning user mobility is stored in a central database with security procedures (login, encryption). Although we collect individual data regarding users' movements, the only stored information related with person identification is the user email, in order to allow login and exchange of information with the system. All data is manipulated without user identification reference. 


\section{B. Route Guidance}

Route guidance is performed using a developed service that includes a class called Dijkstra, which is a personalized implementation of Dijkstra routing algorithm [28]. In our implementation we use a cost function based on time over an array of nodes that represents the road infrastructure, where each road corner is a node. Each adjacent node is connected by an arc with an associated time as a cost. This time is based on distance and bicycle average speed, which depends on several factors, like bicycle effort, road altitude, charge available and also, weather. This approach looks for short cost (time) among the diversity of available paths. Google Maps API is used to represent the suggested route based on GPS coordinates of route nodes.

\section{Range Prediction}

The range prediction for EBs is more complex than for electric vehicles, mainly due to the parameters involved, such as the topography (steepness of the hills), and the energy delivered by the cyclist. The cyclist's effort (power in watts) is taken from the cyclist's profile, together with the bicycle weight and type. This information is combined with the battery SoC level, route topology and weather conditions, in a Data Mining (DM) approach based on the Naive Bayes (NB) algorithm. We chose this probabilistic approach to avoid a complex deterministic approach where we would need to input the cyclist's weight, type of tires and pressure, wind speed and direction. Therefore, using the Bayes theorem:

$$
P\left(\Delta R \mid D_{k}\right)=\frac{P\left(D_{k} \mid \Delta R\right) P(R)}{P\left(D_{k}\right)} \propto P\left(D_{k} \mid \Delta R\right) P(\Delta R),
$$

where $\Delta R$ is the range change in $\mathrm{km}$ (from real range measured less range estimated based on a deterministic approach) and $D_{k}$ are the discrete classes considered: $D_{l}$ is the SOC level ( $100 \%$ means fully charged), $D_{2}$ is the accumulated route altitude per $100 \mathrm{~km}, D_{3}$ is the bicycle effort in watts, $D_{4}$ is the weather information, $D_{5}$ is the distance in $\mathrm{km}, D_{6}$ average speed and $D_{7}$ is the cyclist's weight. We assume independence between these events, so we have:

$$
\begin{aligned}
& P\left(D_{k} \mid \Delta R\right)=P\left(\left\{D_{1}, \mathrm{D}_{2}, \mathrm{D}_{3}, \mathrm{D}_{4}, \mathrm{D}_{5}, \mathrm{D}_{6}, \mathrm{D}_{7}\right\} \mid \Delta R\right)=P\left(D_{1} \mid \Delta \mathrm{R}\right) \\
& P\left(D_{2} \mid \Delta R\right) P\left(D_{3} \mid \Delta R\right) P\left(D_{4} \mid \Delta R\right) P\left(D_{5} \mid \Delta R\right) P\left(D_{6} \mid \Delta R\right) P\left(D_{7} \mid \Delta R\right)
\end{aligned}
$$

These values are estimated based on past profile data, which is used as a training set. For NB application these variables $D_{k}$ and $\Delta R$ are transformed into pre-defined classes to use discrete data. The outputs of this process are probabilities of range change, based on $D_{k}$ events. The higher value is taken to tune the deterministic range by a distance change identified in the higher probability result. Fig. 13 shows the flow of information, where first the range was calculated (deterministically) taking into account the SoC level, battery type, bicycle weight, and the engine type. This value is then optimized in a second processing phase, which uses profile data (see Table III), route altitude, average power applied in route, distance performed, weather information and associated battery SoC decrease rate, in order to tune this range. Past data is used as training data for the classification problem for an NB approach, where a percentage of range change is estimated, because NB classifiers require the estimation of
TABLE III. Representation of selected data of the cyclist profile.

\begin{tabular}{|c|c|c|c|c|c|c|c|}
\hline SL & Time & EL & $\begin{array}{c}\text { Dist. } \\
(\mathrm{km})\end{array}$ & $\begin{array}{c}\text { AS } \\
(\mathrm{km} / \mathrm{h})\end{array}$ & $\begin{array}{c}\text { SoC } \\
\text { level }\end{array}$ & $\begin{array}{c}\text { Weather } \\
\text { Temp./ }\end{array}$ & $\begin{array}{c}\text { Altitude } \\
(\mathrm{m})\end{array}$ \\
\hline A & $9 \mathrm{~h} 15 \mathrm{~m}$ & B & 23 & 12 & N/A & $25^{\circ} \mathrm{C} / \mathrm{S}$ & 230 \\
\hline C & $16 \mathrm{~h} 30 \mathrm{~m}$ & D & 15 & 10 & N/A & $17^{\circ} \mathrm{C} / \mathrm{R}$ & 400 \\
\hline E & $10 \mathrm{~h} 05 \mathrm{~m}$ & F & 31 & 24 & $35 \%$ & $12^{\circ} \mathrm{C} / \mathrm{C}$ & 76 \\
\hline
\end{tabular}

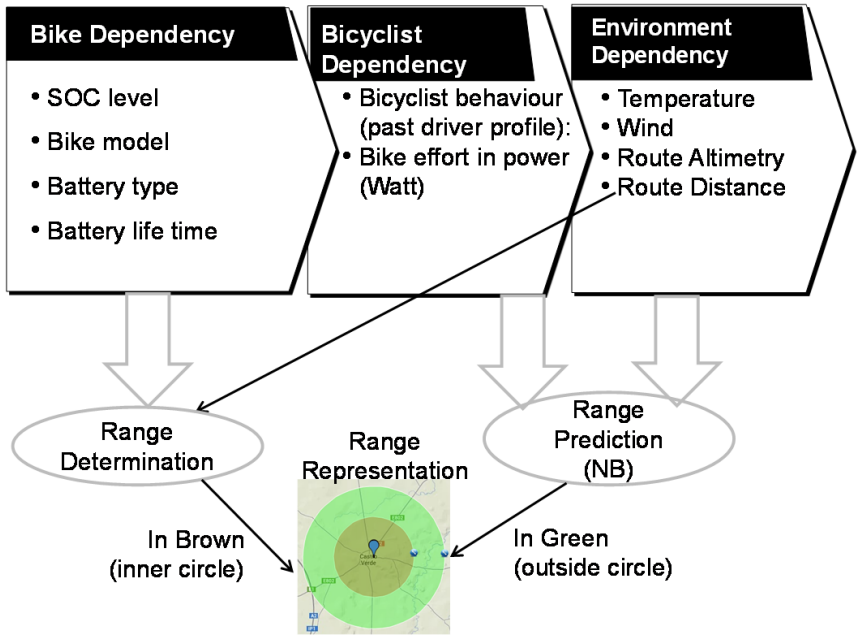

Fig. 13. Flow of information of prediction models.

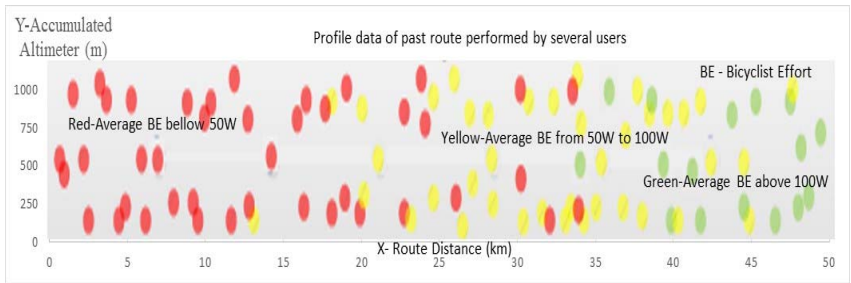

Fig. 14. Representation of profile data in three dimensions: Route distance in $\mathrm{km}$ (X-axis); Accumulated route altimetry (Y-axis); and Cyclist effort simplified to three main classes: red (below $50 \mathrm{~W}$ ), yellow (50 W to $100 \mathrm{~W}$ ) and green (above $100 \mathrm{~W}$ ).

probabilities, and the continuous explanatory attributes are not so easy to handle, as they often take too many different values for a direct estimation of frequencies. The discretization of data is based on the allocation of data into classes based in a clustering approach of existing data [33]. By clustering, main data groups are identified, and a central element to group representative data is used. More details are presented in [34]. Fig. 14 shows data available in the profile related with the travelled route distance in $\mathrm{km}$ and accumulated altitude. The cyclist's effort is divided into three classes (for representation simplification purposes). From the current data of bicycle effort we identified 12 classes that are used on NB approach to determinate the percentage of range change due to the cyclist's effort and route altitude. Weather is also an important parameter (because temperature could be related with bicycle effort) as well as the wind speed and direction. At the charging process it is possible to define the charge needed to reach a destination using the same approach. The MCS is prepared to recommend routes based on the available battery SoC level, with the estimation of the cyclist's effort needed to reach the desired destination. This effort is expressed in a percentage of 


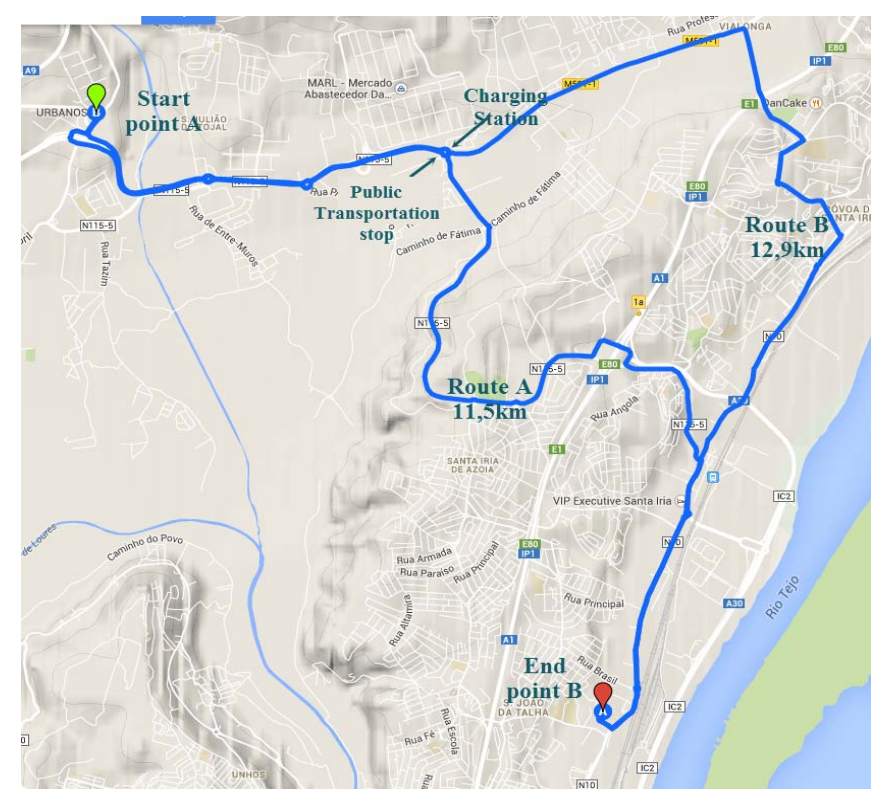

Fig. 15. Representation of route A versus route B. Route A has $11.4 \mathrm{~km}$ with an accumulated altitude of $165 \mathrm{~m}$, whereas route B has $12.9 \mathrm{~km}$ with an accumulated altitude of $51 \mathrm{~m}$.

the previous average effort made by the cyclist, which is available in his profile.

\section{System Evaluation}

In this section we highlight some of the achieved results, taken from the usage or our MCS prototype by local academic staff. We collected more than 300 routes in a 6-month period with twenty different users in Lisbon area (urban cycling paths with frequent stops). Cyclists were 16 male and 4 female, with ages from 20 to 60 years old and weights from $50 \mathrm{~kg}$ to $110 \mathrm{~kg}$. In this population, five cyclists usually ride at weekends, as exercise practice. These cyclists exerted more effort (cadence and power output), achieving higher average speed. Time results also show performance improvements in terms of the cyclists' average speed along the 6-month period. Average speeds ranged from $5 \mathrm{~km} / \mathrm{h}$ to $35 \mathrm{~km} / \mathrm{h}$, with maximum speeds around $58 \mathrm{~km} / \mathrm{h}$.

The routing algorithms show good performance, indicating the shortest time path, taking into account the weather, altitude, bicycle effort and battery charge. Table III, shows an excerpt of the cyclist's profile. Information is stored by route performed, with the indication of start location (SL), time, end location (EL), distance performed in $\mathrm{km}$, average speed (AS), SoC level (where we indicate the decrease percentage value, or N/A - not applicable, if the bicycle does not have an electric engine), temperature (in Celsius), altitude, as well as weather information: Sunny day (S), Rainy day (R), Cloudy day (C), or Windy day (W).

Fig. 15 shows a representative case of our routing approach. Route A has $11.4 \mathrm{~km}$ with an accumulated altitude of $165 \mathrm{~m}$, which, normalized per $100 \mathrm{~km}$, corresponds to $1447 \mathrm{~m}$, whereas Route B has $12.9 \mathrm{~km}$ with an accumulated altitude of $51 \mathrm{~m}(395 \mathrm{~m}$ per $100 \mathrm{~km})$. The proposed route (A) has $1.4 \mathrm{~km}$ more, but the accumulated altitude is $1052 \mathrm{~m}$ less per $100 \mathrm{~km}$. A third route through a motorway is not shown because, by law, it cannot be used by EBs). The cyclist profile registers different speeds for different accumulated altitude values. For simplification, we start our analysis with a conventional bicycle. For a given cyclist, speed is, on average, $20 \mathrm{~km} / \mathrm{h}$ for accumulated altitudes lower than $500 \mathrm{~m}$ per $100 \mathrm{~km}$, and decreased to $14 \mathrm{~km} / \mathrm{h}$ for accumulated altitudes around $1500 \mathrm{~m}$ per $100 \mathrm{~km}$. Therefore, the cyclist is able to perform route A in 49 minutes and route $\mathrm{B}$ in 39 minutes (10 minutes less). When we consider the use of the electric engine and the corresponding energy consumption, results from the tests performed show that, on average, route B takes $2 \%$ to 5\% less bicycle energy than route A, depending on the cyclist's effort. With an electric bicycle the route time of $\mathrm{A}$ is shorter than $\mathrm{B}$, but it uses up more battery energy. This means that the route advice depends on the user's main goal: save energy or save time. We also tested the provisioning of advice regarding public transport and charging stations. Taking into account the data shown on Fig. 15, as well as public transport stops and charging station locations, it is possible to receive information and provide advice regarding when the SoC level is low (if energy available does not allow the user to go and return). In this case, the user receives the location of the nearest charging station and the public transport schedules in that window time. Range prediction based on current approach shows better results than the deterministic ones, but we still need to improve. For example taking into account route A and B on Fig. 15, the initial range of $30 \mathrm{~km}$ is changed from user to user and also based on the route performed. We have cases in which users can increase this value by $50 \%$ and results show improvements near this percentage value. The weather influences the cyclists' effort, because there is a reduction in cadence (rpm) and power output (W) on sunny hot days $(20 \%$ on average), according to the collected data. Besides, wind speed and direction have influence on the cycling speed for similar effort levels.

To get feedback about MCS usage, we performed an online survey (with predefined questions and one last field where users could freely add their comments) applied to the testing population (20 users). This survey shows positive remarks regarding the route selection advice provided by the proposed system, which takes into account information such as the route altimetry or the remaining battery energy, unlike other route planning software such as Google Maps. Some users presented concerns about: (1) Communication cost associated with MCS maps representation and data store and processing. The impact of this is mainly due to maps downloads, and this maps data can be previous downloaded to decrease this communication process. MCS data transfer and central processing is very small. (2) Mobile device power consumption during the riding process. To overcome this problem there are several market solutions that use bike wheel rotation to generate energy to feed devices through a USB connection. In [35] is presented one example of this type of solution. An alternative to this is to feed the mobile device with energy from the battery (this energy consumption is residual and does not affect significantly the EB autonomy). 


\section{CONCLUSIONS}

Mobile devices and real time information systems will play an important role in people's lives in this century and, associated with the proliferation of Electric Bikes (EBs), will contribute to the expansion of electric mobility. Consequently, these technologies will contribute to the development of Smart Cities and will improve the citizens' quality of life. The results presented in this paper are a contribution to the expansion of electric mobility, helping the integration of cyclists and theirs EBs. In order to provide a much more reliable journey planning, the MCS App proposed in this paper, in collaboration with geographic information systems, can help to deal with the cyclist range anxiety problem. This application provides the cyclist with a range prediction, aiming to check if a desired destination can be achieved without the requirement of a stop to perform the battery charging process, or even if it is necessary to increase the cyclist's effort. With external sensors for the cyclist, it is possible to check heart rate, and to generate alerts, if certain pre-defined limits are achieved. The developed MCS App can also provide information of schedules from different public transport systems to the cyclist and consequent route planning with update information from public transport operators. Mining each user's travel information (profile), collected by mobile devices and external sensors has the potential to address personalization issues in the mobility process and provide useful information regarding public transport usage and user mobility patterns.

The MCS App is also a route planning software especially tuned for EBs because it uses weather and route altimetry information, as well as the energy available in EB battery, and offers an interface for public transportation with information regarding bus stop locations and schedules. This is an important contribution of the MCS described in this paper, which makes difference to other route advice systems and is one of the first approaches to this problem using Google Maps for route representation.

The proposed MCS system is also being used in an application developed for conventional bicycles to collect relevant real time data about the performance of professional cyclists in competition and training environment.

\section{REFERENCES}

[1] C. C. Chan, "The State of the Art of Electric, Hybrid, and Fuel Cell Vehicles," Proceedings of the IEEE, vol.95, no.4, pp.704-718, Apr. 2007.

[2] Seshadri Srinivasa Raghavan, Alireza Khaligh, "Electrification Potential Factor: Energy-Based Value Proposition Analysis of Plug-In Hybrid Electric Vehicles," IEEE Trans. Veh. Technol., vol.61, no.3, pp.1052-1059, Mar. 2012.

[3] Julian Timpner, Lars Wolf, "Design and Evaluation of Charging Station Scheduling Strategies for Electric Vehicles," IEEE Trans. Intell. Transp. Syst., vol.15, no.2, pp.579-588, Apr. 2014.

[4] Saeid Bashash, Hosam K. Fathy, "Cost-Optimal Charging of Plug-In Hybrid Electric Vehicles Under Time-Varying Electricity Price Signals," IEEE Trans. Intell. Transp. Syst., vol.15, no.5, pp.1958-1968, Oct. 2014.

[5] A. Y. Saber, G. K. Venayagamoorthy, "Plug-in vehicles and renewable energy sources for cost and emission reductions," IEEE Trans. Ind.
Electron., vol.58, no.4, pp.1229-1238, Apr. 2011.

[6] Jun Hua Zhao, Fushuan Wen, Zhao Yang Dong, Yusheng Xue, Kit Po Wong, "Optimal Dispatch of Electric Vehicles and Wind Power Using Enhanced Particle Swarm Optimization," IEEE Trans. Ind. Inform., vol.8, pp.889-899, Nov. 2012.

[7] Fabian Kennel, Daniel Görges, Steven Liu, "Energy Management for Smart Grids with Electric Vehicles based on Hierarchical MPC," IEEE Trans. Ind. Inform., vol.9, no.3, pp.1528-1537, Aug. 2013.

[8] Wencong Su, Habiballah Rahimi-Eichi, Wente Zeng, Mo-Yuen Chow, "A Survey on the Electrification of Transportation in a Smart Grid Environment," IEEE Trans. Ind. Inform., vol.8, pp.1 10, Feb. 2012.

[9] Andrea G. Bianchessi, Carlo Ongini, Ivo Boniolo, Giovanni Alli, Cristiano Spelta, Mara Tanelli, Sergio M. Savaresi, "A Novel Electric Vehicle for Smart Indoor Mobility," IEEE Trans. Intell. Transp. Syst., vol. P, no.99, pp.1-1, 2014.

[10] Manuele Bertoluzzo, Giuseppe Buja "Development of Electric Propulsion Systems for Light Electric Vehicles,“ IEEE Trans. Ind. Inform., vol.7, no.3, pp.428-435, Aug. 2011.

[11] P. Spagnol, G. Alli, C. Spelta, P. Lisanti, F. Todeschini, S. M. Savaresi, A. Morelli, "A full hybrid electric bike: how to increase human efficiency," IEEE American Control Conference, pp. 2761-2766, June 2012.

[12] D. Schneider, "Easy rider," IEEE Spectrum, vol.46, no.9, pp.26-27, Sept. 2009.

[13] Marc Beaudin, Hamidreza Zareipour, Anthony Schellenberglabe, William Rosehart, "Energy storage for mitigating the variability of renewable electricity sources: An updated review," Journal of Energy for Sustainable Development, Elsevier, vol.14, no.4, pp.302-314, Dec. 2010 .

[14] Ahmed Yousuf Saber, Ganesh Kumar Venayagamoorthy, "Plug-in vehicles and renewable energy sources for cost and emission reductions," IEEE Transactions on Industrial Electronics, vol.58, no.4, pp.1229-1238, Apr. 2011.

[15] V. Gungor, D. Sahin, T. Kocak, S. Ergut, C. Buccella, C. Cecati, G. Hancke, "Smart grid technologies: Communications technologies and standards," IEEE Trans. Ind. Inform., vol.7, no.4, pp.529-539, Nov. 2011.

[16] V. C. Gungor, B. Lu, G. P. Hancke, "Opportunities and challenges of wireless sensor networks in smart grid," IEEE Trans. Ind. Inform., vol.57, no.10, pp.3557-3564, Oct. 2010.

[17] Chunhua Liu, K. T. Chau, Diyun Wu, S.huang Gao, "Opportunities and Challenges of Vehicle-to-Home, Vehicle-to-Vehicle, and Vehicle-toGrid Technologies," Proceedings of the IEEE, vol.101, no.11, pp.24092427, Nov. 2013.

[18] "ICT for the Fully Electric Vehicle Research Needs and Challenges Ahead," 2nd Edition, May 2011 (Mar. 2014). [online] Available: http://cordis.europa.eu/fp7/ict/micro-nanosystems/docs/brochure-ictfor-fev-2nd-edition-011_en.pdf

[19] Adrian Timbus, Mats Larsson, Cherry Yuen, "Active Management of Distributed Energy Resources Using Standardized Communications and Modern Information Technologies," IEEE Trans. Ind. Electron., vol.56, no.10, pp.4029-4037, Oct. 2009.

[20] Raluca Marin-Perianu, Mihai Marin-Perianu, Paul Havinga, Simon Taylor, Rezaul Begg, Marimuthu Palaniswami, David Rouffet, "A performance analysis of a wireless body-area network monitoring system for professional cycling," Springer Pers. Ubiquit. Comput., Nov. 2011.

[21] S. B. Eisenman, E. Miluzzo, N. D. Lane, R. A. Peterson, G.-S. Ahn, A. T. Campbell, "The BikeNet mobile sensing system for cyclist experience mapping," 5th Int. Conference on Embedded Networked Sensor Systems, Sydney, Australia, 2007.

[22] Christine Outram, Carlo Ratti, Assaf Biderman, "The Copenhagen Wheel: An innovative electric bicycle system that harnesses the power of real-time information and crowd sourcing," EVER'2010, Monaco, Mar. 2010.

[23] Hiroaki Suzuki, Robert Cervero, Kanako Iuchi, "Transforming cities with transit: transit and land-use integration for sustainable urban development," World Bank Publications, vol. 1, 2013. 
[24] Brahima Sanou, (Mar. 2014) [online] Available: http://www.itu.int/en/ITUD/Statistics/Documents/facts/ICTFactsFigures2013-e.pdf

[25] João C. Ferreira, Vítor Monteiro, João L. Afonso, "Vehicle-toAnything Application (V2Anything App) for Electric Vehicles," IEEE Trans. Industrial Informatics, Nov. 2013.

[26] João C. Ferreira, Vítor Monteiro, João L. Afonso, A. Silva, "Smart Electric Vehicle Charging System," IEEE IVS 4th International Intelligent Vehicles Symposium, Baden-Baden Germany, pp.758 763, June 2011.

[27] Joao Ferreira, Vítor Monteiro, Joao L. Afonso, "Moby.Cockpit Project for EV Seamless Integration in the Cooperative Transport Infrastructure," International Conference on IT and Intelligent Systems, 28-29 August, Malaysia, 2013.

[28] João Ferreira, "Green Route Planner. Nonlinear Maps and their Applications," Selected Contributions from the NOMA 2011 International Workshop. Series: Springer Proceedings in Mathematics \& Statistics, vol.71. Grácio, C.; Fournier-Prunaret, D.; Ueta, T.; Nishio, Y. (Eds.), Dec. 2013.

[29] Renato Lourenço, Paulo Leite, André Lourenço, Hugo Silva, Ana Fred, David Coutinho, "Experimental Apparatus for Finger ECG Biometrics," International Conference on Biomedical Electronics and Devices - Biodevices, pp.196-200, Feb. 2012.

[30] Jennifer R. Kwapisz, Gary M. Weiss, Samuel A. Moore, "Activity recognition using cell phone accelerometers," ACM SIGKDD Explorations Newsletter, vol.12, no.2, pp.74-82, Dec. 2010.

[31] Yu Zheng, Yukun Chen, Quannan Li, Xing Xie, Wei-Y. Ma, "Understanding transportation modes based on gps data for web applications," ACM Trans. on the Web, vol.4, no.1, Jan. 2010.

[32] Michael Armbrust, Armando Fox, et al., "A view of cloud computing", Communications of the ACM, vol.53, no.4, pp. 50-58, Apr. 2010.

[33] A. K. Jain, M. N. Murty, P. J. Flynn, "Data Clustering: A Review," ACM Computing Surveys, vol.31, no.3, Sept. 1999.

[34] João C. Ferreira, Vítor Monteiro, João L. Afonso, "Dynamic Range Prediction for an Electric Vehicle," 27th Electric Vehicle Symposium (EVS27), Barcelona - Spain, Nov. 2013.

[35] Cycling About, List of Hub Dynamo Power Supplies for USB Devices (June 2015) [online] Available: http://cyclingabout.com/list-of-hubdynamo-power-supplies-for-usb-devices/

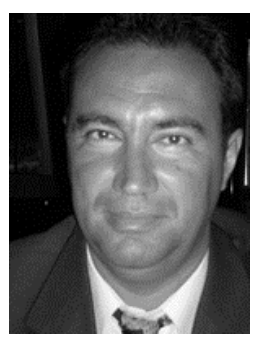

João C. Ferreira is Professor at the Polytechnic Institute of Lisbon (IPL/ISEL) and Consultant with different companies and institutions. He graduated in Physics at the Technical University of Lisbon (UTL/IST), Portugal, received an $\mathrm{MSC}$ in Telecommunication and a $\mathrm{PhD}$ degree in Computer Science Engineering from UTL/IST. His professional and research interests are in retrieval, geographic and multimedia retrieval, Electric Vehicle, Intelligent Systems, intelligent transportation (ITS) and sustainable mobility systems. He is the author of over 140 scientific papers of international conferences and workshops in different areas of computer science.

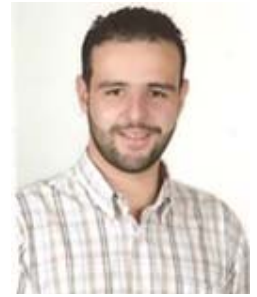

Vítor Monteiro (S'10) was born in Guimarães, Portugal, on May 1984. He received the M.Sc. in Industrial Electronics and Computers Engineering, from the School of Engineering of the University of Minho, in 2012. Since 2008 he is a member of the Group of Energy and Power Electronics (GEPE) of the Centro Algoritmi, at the University of Minho. Currently he is a PhD student supported by the doctoral scholarship SFRH/BD/80155/2011 granted by the Portuguese FCT agency, and a collaborator of the Centro Algoritmi of the University of Minho. His research interests are related with Power Electronics Converters, Digital Control Techniques, Smart Grids, and Electric Vehicles.

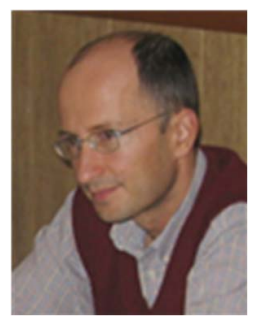

José Augusto Afonso (M'99) was born in Rio de Janeiro, Brazil, in 1968. He received the Electronic Engineering degree from the Federal University of Rio de Janeiro (UFRJ), Brazil, in 1993, the M.Sc. degree in Informatics from the University of Minho, Portugal, in 1997, and the Ph.D. degree in Industrial Electronics from the University of Minho, in 2005. Since 1997, he has been with the Department of Industrial Electronics of University of Minho, where he is an Assistant Professor. He is a researcher with the CMEMS-UMinho R\&D center of University of Minho. His research interests include: Wireless Communications, Body Area Networks, Mobile Sensing, Wireless Sensor Networks and Medium Access Control protocols.

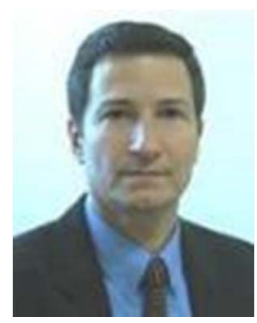

João Luiz Afonso (M’00) was born in Rio de Janeiro, Brazil, in 1963. He received the B.S. and M.Sc. degrees in Electrical Engineering from the Federal University of Rio de Janeiro in 1986 and 1991, respectively, and the Ph.D. degree in Industrial Electronics from the University of Minho, Guimarães, Portugal, in 2000. Since 1993, he has been with the Department of Industrial Electronics, University of Minho, where he is Associate Professor. He teaches Electrical Machines, Electrical Energy Systems, Complements of Power Electronics, Electrical Power Quality, Active Power Filters and Renewable Energy. He is a researcher with the Group of Energy and Power Electronics (GEPE), and he coordinates the thematic strand of Sustainable and Smart Cities of the Centro Algoritmi. His research interests include: Power Quality, Active Power Filters, Renewable Energy, Electric Vehicles, Energy Efficiency, Energy Storage Systems, Smart Grids and Smart Cities. 